\title{
Síndrome braquicefálica - estenose de narinas em cão
}

\author{
Brachycephalic syndrome - nostril stenosis in dog \\ Amarílis Díaz de Carvalho ${ }^{1,2}$, Ana Cristina Pacheco de Araújo ${ }^{3}$, Leandro Haczkiewicz Gaiga ${ }^{3}$ \\ \& Rubem Lundgven Cavalcante ${ }^{4}$
}

\begin{abstract}
RESUMO
Frequentemente observado em raças braquicefálicas, a estenose de narinas pode ocasionar importantes alterações secundárias. O fluxo aéreo para o interior da cavidade nasal fica restrito e torna-se necessário um esforço inspiratório maior, causando dispneia leve à intensa. A síndrome braquicefálica refere-se a uma combinação de estenose de narinas, alongamento de palato mole e eversão de sacos laringianos, comumente observadas nestas raças. Estes animais exibem sinais de obstrução de via aérea superior decorrente de anormalidades anatômicas e funcionais. A afecção afeta qualquer sexo e mais comumente em cães que em gatos. Apresentam respiração difícil e ruidosa, intolerância ao exercício, cianose e sono inquieto. O diagnóstico deve ser feito através do exame físico. Deve-se avaliar radiografias torácicas para detectar anormalidades cardíacas ou pulmonares subjacentes. Para aliviar os sinais, exige-se o tratamento cirúrgico das narinas estenosadas. Animais com obstrução respiratória superior constituem riscos anestésicos e pós-operatórios.
\end{abstract}

Descritores: cão, estenose de narina, cirurgia.

\begin{abstract}
Frequently observed in brachycephalic breeds, the nostril stenosis may cause relevant secondary disturbance. The air flow to the nasal cavity becomes limited, obligating to an extra inspiratory effort, causing light to intense dyspneia. The brachycephalic syndrome is a combination of a nostril stenosis, soft palate enlargement and laryngeal eversion, frequently observed in brachycephalic animals. Signs of obstruction of the upper aerial ducts are consequence of anatomical and functional disturbances. Both sexes are affected and dogs are more susceptible than cats. With difficult and noisy breeding, the affected animals are intolerant to physical exercise, showing cyanosis and an agitated sleeping. The diagnosis is possible by physical examination, discarding cardio-pulmonary abnormalities by means radiography. For symptoms release, the surgical treatment of the nostrils, to reduce the stenosis, is indicated. Nevertheless, the respiratory obstruction is a risk factor during the anesthesia and post-surgery period.
\end{abstract}

Keywords: dog, nostril stenosis, surgery.

${ }^{1}$ Programa de Pós-graduação em Ciências Veterinárias da Universidade Federal do Rio Grande do Sul (PPGCV-UFRGS), Faculdade de Veterinária, Universidade Federal do Rio Grande do Sul (UFRGS), Av. Bento Gonçalves no. 9090, 91540-000 Porto Alegre, Bairro Agronomia, RS, Brasil. ${ }^{2}$ Laboratório de Anatomia Animal, Faculdade de Veterinária - UFRGS. ${ }^{3}$ Médico Veterinário Autônomo. ${ }^{4}$ Mestrando do Departamento de Farmacologia, Instituto de Ciências Básicas da Saúde - UFRGS. CORRESPONDÊNCIA: A.D. Carvalho [amarílis@bnet.com.br; FAX + 55 (51) 3308-6122]. 


\section{INTRODUÇÃO}

A estenose das narinas é observada comumente em raças braquicefálicas de pequeno e grande porte $[2,3,7]$. O termo Síndrome Braquicefálica se refere a uma combinação de estenose das narinas, alongamento de palato mole [4] e eversão de sáculos laringianos [5].

As raças mais afetadas são: Buldog Inglês, Boston Terriers, Pequinês, Pug, Shih Tzus, Boxer, Lhasa Apso, Mastif [2,4,5-8]. A síndrome é importante devido à gravidade dos sinais clínicos e em seu potencial risco de morte [2].

Foi verificada a prevalência de anomalias ou malformações anatômicas nos cães clinicamente afetados com a síndrome braquicefálica sendo que a estenose das narinas ocorre em aproximadamente $50 \%$ dos casos [2]. Nas raças braquicefálicas é indicado realizar a correção cirúrgica das narinas estenóticas o mais jovem possível, já que os cães menores de dois anos submetidos à cirurgia têm um melhor prognóstico, diferentemente dos que sofrem desta síndrome durante muitos anos [7].

A proposta deste trabalho é de relatar um caso de estenose de narinas ocorrido em um cão filhote da raça Shih Tzu, que foi atendido em uma clínica particular em Porto Alegre, Rio Grande do Sul, Brasil.

\section{RELATO DE CASO}

Foi atendido, em uma clínica particular, um canino, macho, da raça Shih Tzu, de três meses de idade que apresentava dificuldade respiratória com ruídos noturnos, dispneia, dificuldade inspiratória e cavidade oral sempre aberta. Ao exame clínico observou-se uma diminuição da abertura das narinas (Figura 1), sem prolongamento do palato mole (diagnóstico confirmado no ato anestésico - intubação) e com uma dificuldade inspiratória e expiratória severa (animal sempre cansado). Devido à pouca idade apenas um hemograma foi realizado para o ato cirúrgico, não apresentando alteração.

$\mathrm{O}$ paciente foi submetido à anestesia, sendo administrado Cloridrato de tramadol $2 \mathrm{mg} . \mathrm{Kg}^{-1}$ como medicação pré-anestésica, e em seguida, a indução foi feita com propofol $3 \mathrm{mg} . \mathrm{Kg}^{-1}$ e midazolan $0,4 \mathrm{mg} \cdot \mathrm{Kg}^{-1}$ e a manutenção anestésica com isoflurano. $\mathrm{O}$ animal foi, então, posicionado em decúbito esternal, e a tricotomia foi feita, seguida da antissepsia. Foi retirado um segmento em cunha da asa de cada narina (Figu- ra 2), sendo feita a sutura (Figura 3) com pontos isolados simples utilizando poligalactina 910 (vicryl 40 ). Após o ato cirúrgico o animal permaneceu intubado até sua total recuperação. Após a extubação, foi possível observar a melhora, principalmente do quadro inspiratório da respiração do filhote. Houve pouco sangramento e o animal recebeu alta com a indicação do uso por no mínimo sete dias do colar elizabetano. Transcorrido este período foi visto que houve a queda natural da sutura com total cicatrização local.

Após dois meses o animal retornou (Figura 4) com total recuperação e abertura normal das narinas, não sendo mais relatado pelo proprietário dificuldades respiratórias ou a presença de ruídos noturnos.

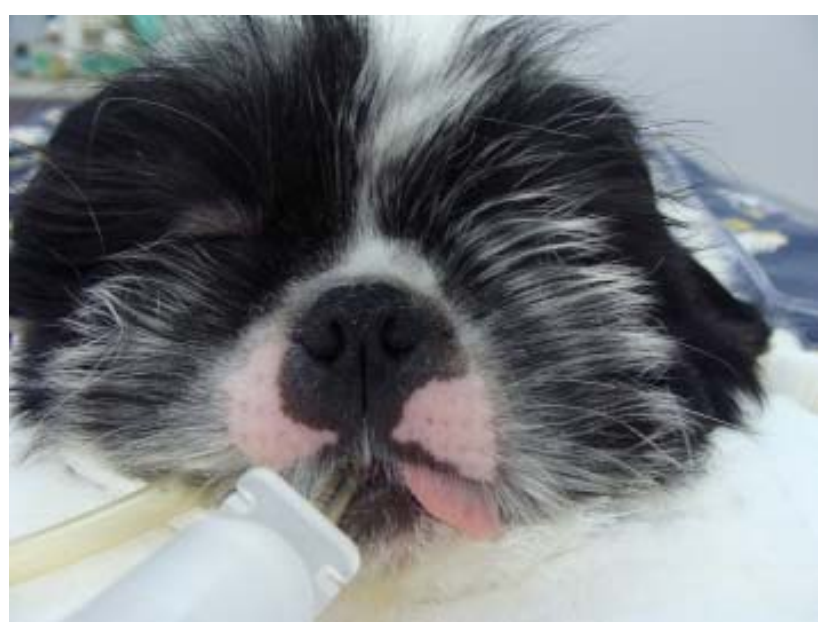

Figura 1. Imagem em vista rostral do paciente, evidenciando as narinas estenosadas.

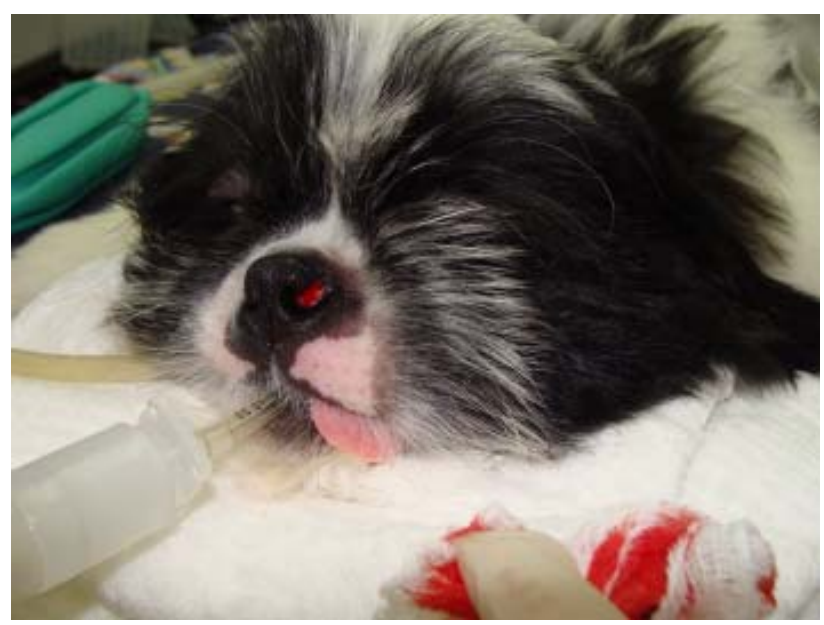

Figura 2. Imagem em vista rostro-lateral do paciente, mostrando a incisão na asa da narina esquerda. 


\section{DISCUSSÃO}

A afecção afeta qualquer sexo. A estenose das narinas encontra-se presente no nascimento; no entanto, muitos animais são apresentados para avaliação entre 2 a 4 anos de idade [3]. Nas raças braquicefálicas é indicado realizar a correção cirúrgica das narinas estenóticas o mais jovem possível [7], o que foi feito no caso descrito.

Conforme a literatura, pacientes com obstrução de via aérea superior geralmente apresentam respiração difícil, ruidosa [3-5] e respiração pela boca [6,7], sendo exatamente o observado no caso. Animais com orifícios nasais estenosados, durante a inspiração, apresentam deslocamento medial da asa da narina, colapsando e fechando o espaço aéreo. No animal em questão pode ser observado que a obstrução foi parcial sendo possível verificar a respiração nasal dificultada [2].

O diagnóstico da síndrome braquicefálica baseia-se no histórico de obstrução das vias aéreas superiores ocorrendo em raças sabidamente predispostas à síndrome [2] e deve ser identificada em exame físico [3,5] durante a anamnese.

O tratamento da síndrome braquicefálica visa desobstrução das vias aéreas superiores através da correção cirúrgica das anormalidades anatômicas existentes $[2,4,7]$.

No caso descrito a técnica cirúrgica utilizada foi a de ressecção em cunha nasal $[1,6,7]$ onde é feita uma excisão em cunha estendendo-se a partir da asa da narina caudalmente para incluir parte da cartilagem alar, sendo essa a técnica de eleição. A base da cunha deve incluir um terço a metade da borda livre da narina [1].

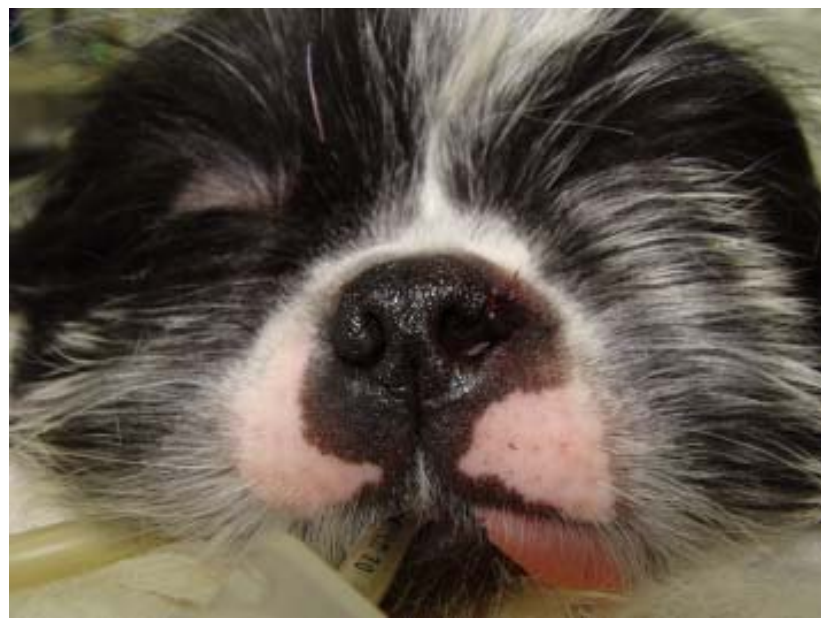

Figura 3. Imagem em vista rostral mostrando a sutura na asa da narina esquerda e a narina direita ainda com a estenose.

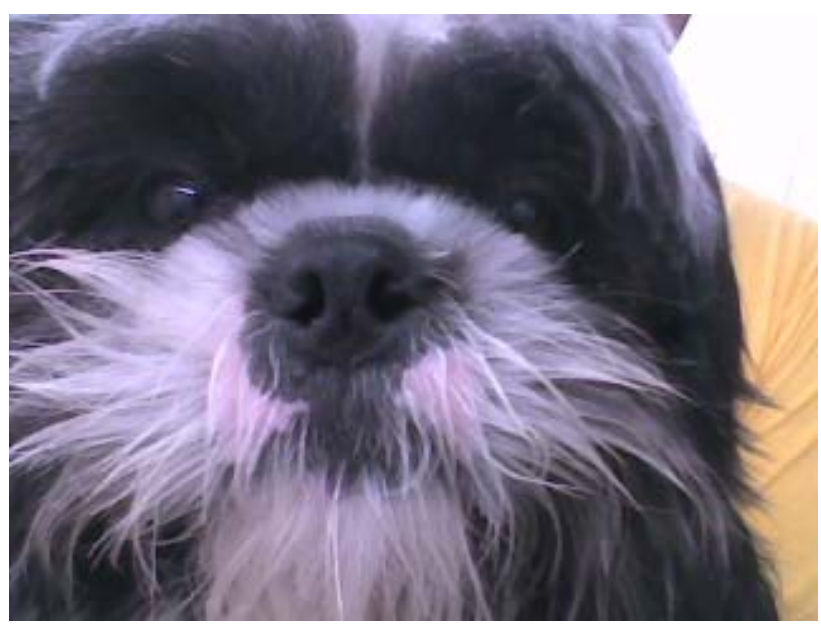

Figura 4. Imagem após dois meses da cirurgia. Cicatrizações perfeitas, não se observam mais sinais de estenose de narina.

\section{REFERÊNCIAS}

1 Bichard S. J. \& Sherding R.G. 1998. Sistema Respiratório. In: Manual Saunders: Clínica de Pequenos Animais. São Paulo: Roca, pp.619-620.

2 Docal C.M. \& Camacho A.A. 2008. Síndrome braquicefálica: aspectos clínicos e importância de exames eletrocardiográficos e radiográficos na avaliação de alterações cardíacas secundárias à síndrome. Waltham News. 3: 2-6.

3 Fossum T.W. \& Duprey L.P. 2005. Cirurgias do Trato Respiratório Superior. In: Cirurgia de Pequenos Animais. São Paulo: Roca, pp.726-729.

4 Gómez-Ochoa P. 2000. Síndrome braquicefálico y colapso traqueal: diagnóstico y tratamiento. 5p. Disponível em: <http:/ /www.cldavis.org/cgi-bin/download.cgi?pid=343>. Acessado em 04/2009.

5 Massó J.F.B., Machado J.E., Albertus J.C.C. \& Garcia S.M. 2007. Revisión del braquicefálico y su abordaje quirúrgico. Argos Informativo Veterinário. 87: 52-56.

6 Morales-López, J.L. 2000. Síndrome braquicefálico. 19 p. Disponível em: <http: //www. uco.es/organiza/departamentos/ anatomia-y-anat-patologica/peques/braquio2004.pdf>. Acessado em 04/2009. 
7 Orozco S.C. \& Gómez L.F. 2003. Manejo médico y quirúrgico del síndrome de las vías aéreas superiores del braquicéfalo. Revista do Colégio de Ciencias Pecuarias. 16: 162-170.

8 Rossi C.N. 2008. Raças braquicefálicas e as doenças genéticas mais comuns. In: Resumos das palestras proferidas durante o $8^{\circ}$ COMPAVEPA. (São Paulo, Brasil). pp.45-46. 